\title{
Dinâmica de preços e quantidades exportadas de produtos florestais brasileiros, 1995-2013
}

\author{
Thiago Taglialegna Salles ${ }^{1}$, Crismeire Isbaex ${ }^{1 *}$, Márcio Lopes da Silva1 ${ }^{1}$, Sebastião Renato Valverde ${ }^{1}$, Tarço Murilo Oliveira Luz ${ }^{2}$ \\ 1 Universidade Federal de Viçosa, Av. Peter Henry Rolfs, s/n, CEP 36570-900, Viçosa, MG, Brasil \\ ${ }^{2}$ Universidade Federal dos Vales do Jequitinhonha e Mucuri, Rod. MGT 367, Km 583, 5000, Alto da Jacuba, CEP $39100-000$, Diamantina, MG, Brasil
}

"Autor correspondente:
crismeireisbaex@hotmail.com

Termos para indexação:

Comércio internacional

Comércio de produtos florestais

Economia florestal

Index terms:

International trade

Forest products trade

Forest economy

Histórico do artigo:

Recebido em 23/09/2015

Aprovado em 15/09/2016

Publicado em 30/12/2016

doi: 10.4336/2016.pfb.36.88.1049
Resumo - O objetivo deste artigo foi analisar as variações no preço e na quantidade exportada de polpa de celulose, painéis de madeira, madeira serrada e papel pelo Brasil e a sua relação com a demanda e oferta, no período 1995-2013. Foram organizados graficamente dados da FAO relacionados à variação de preço e à quantidade exportada ao longo dos anos, sendo calculadas suas taxas de variação média anual através de modelos de tendência. Influenciadas pela vantagem competitiva na produção de matéria prima e por investimentos no setor, as taxas anuais de variação para exportação de polpa de celulose e de papel foram iguais a $10,13 \%$ e $2,60 \%$, respectivamente. Relacionadas com a dinâmica da economia dos EUA, as taxas para exportações de painéis de madeira e madeira serrada foram $5,94 \%$ e $-0,0087 \%$, respectivamente. As taxas de variação dos preços foram iguais a $-3,73 \%$ para polpa de celulose, $-2,35 \%$ para madeira serrada, $-7,35 \%$ para painéis de madeira e $-5,10 \%$ para papel. As tendências de preço acompanharam a cotação do dólar. A oferta de polpa de celulose, painéis de madeira e de papel disponibilizada pelo Brasil no mercado internacional aumentou entre 1995 e 2013 . No entanto, foi observada queda na demanda de madeira serrada, no período analisado.

\section{Dynamics of prices and exported amounts of Brazilian forest products between 1995 and 2013}

\begin{abstract}
The objective of this study was to analyze changes in price and amounts of wood pulp, wood panels, sawn wood and paper exported by Brazil. Additionally, it was also aimed to analyze the relationship between supply and demand in the period of 1995-2013. Data from FAO of price variation and exported amounts over the years were organized graphically, and their annual average change rates were calculated through trend models. Influenced by the competitive advantage in the production of raw materials and investments in the sector, the export annual rates of wood pulp and paper were $10.13 \%$ and $2.60 \%$, respectively. Related to the dynamics of USA economy, export rates of wood panels and sawn wood were $5.94 \%$ and $-0.0087 \%$, respectively. The change rates for prices were $-3.73 \%$ for wood pulp, $-2.35 \%$ for sawn wood, $-7.35 \%$ for wood panels and $-5.10 \%$ for paper. Price trends followed dollar exchange rate. Brazilian supply of wood pulp, wood panels and paper in the international market increased between 1995 and 2013. However, there was a decrease in lumber demand in the same period.
\end{abstract}




\section{Introdução}

O setor florestal contribui significativamente para a economia brasileira. Em 2014, o valor das exportações de produtos madeireiros pelo país foi superior a US\$ 10 bilhões, sendo a celulose o produto mais exportado, tanto em quantidade, quanto em valor. Aliada à aptidão em obter receitas, a atividade florestal tem baixo custo ambiental e grande capacidade de gerar postos de trabalho diretos e indiretos (Vieira, 2006; Sistema Nacional de Informações Florestais, 2015).

Mesmo demandando altos investimentos, a participação das florestas plantadas nos diversos segmentos industriais de transformação da madeira tem se tornado cada vez mais significativa. Tal fato se deve à crescente demanda por matéria-prima florestal, principalmente por parte dos segmentos de celulose e papel, siderurgia, painéis e móveis (Anuário..., 2006).

De acordo com os dados históricos da balança comercial dos setores industriais do Brasil, nove dentre 19 categorias de produtos apresentaram saldo médio positivo no comércio internacional entre 1996 e 2013. A categoria que engloba madeira e seus produtos ficou em terceiro lugar em termos de valores, perdendo apenas para as de alimentos, bebidas e tabaco e de produtos metálicos (Brasil, 2015).

Segundo Radicchi (2004), mesmo quando o cenário relacionado à expansão das exportações encontra-se pouco favorável, a atividade agroindustrial nacional (que inclui o setor florestal), graças ao seu nível tecnológico e sua competitividade externa, se mantém como um dos setores mais produtivos e eficientes do país.

Todavia, segundo Soares et al. (2011a) e Gomes (2014), o setor no Brasil enfrenta desafios, como o câmbio desfavorável, a crise nos países importadores, as barreiras comerciais, o custo Brasil, os investimentos em novas tecnologias e a escassez de mão-de-obra especializada. A crise nos países importadores de produtos florestais brasileiros se destaca devido à vulnerabilidade do Brasil, observada, por exemplo, na crise econômica mundial ocorrida em meados de 2008 e 2009, quando houve impactos negativos no setor florestal do país. Alguns desafios que demandariam ajustes internos ao País dizem respeito ao custo Brasil, que envolve os custos com infraestruturas deficientes, burocracia, processos onerosos de licenciamento ambiental, além de elevadas taxas de juros e carga tributária, encarecendo os produtos brasileiros em relação aos produtos estrangeiros, e aqueles relacionados à tecnologia e mão de obra especializadas, sendo necessário aumentar os investimentos governamentais e do setor privado em pesquisa na área florestal e para o desenvolvimento de cursos para treinamento e/ou formação de profissionais.

O Brasil possui características favoráveis de solo e clima, além de tecnologia silvicultural avançada, ciclos de rápido crescimento e de alta qualidade e elevada produtividade das plantações. Contudo, os desafios que enfrenta fazem com que corra o risco de perder competitividade, como já ocorreu com alguns produtos não madeireiros. Por exemplo, o país não é mais o maior exportador de palmito e deixou de ser o maior exportador de borracha natural há muitos anos (Soares et al., 2011b).

Além de se encontrarem sob a dinâmica de um mercado global, as atividades florestais apresentam particularidades que as diferenciam dos demais setores da economia. Destacam-se o longo prazo, o alto custo para a sua implantação, o problema da escolha da taxa de juros a ser utilizada na formulação e análise de projetos florestais, as várias opções de destino final para a madeira e a presença de externalidades e de bens públicos (Rezende et al., 1996).

Sendo assim, o comportamento dos produtos florestais brasileiros no mercado internacional é de interesse para os profissionais do setor, havendo diversos estudos relacionados ao assunto, como os de Valverde et al. (1999, 2006), Noce et al. (2003), Coelho \& Berger (2004) e Almeida et al. (2010). Desta maneira, o objetivo deste trabalho foi analisar as variações no preço e na quantidade exportada, entre os anos de 1995 e 2013, dos principais produtos florestais comercializados pelo Brasil, e sua relação com a demanda e oferta destes produtos.

\section{Material e métodos}

\section{Referencial teórico}

Foram tomadas como referência as teorias da demanda, oferta e preço de equilíbrio de mercado, como detalhado a seguir.

A demanda por um determinado bem se refere à quantidade que os consumidores desejam comprar deste bem a determinado preço, mantendo-se constantes quaisquer fatores que possam afetar a quantidade demandada (Pindyck \& Rubinfeld, 2005). A demanda 
é normalmente influenciada pelo preço do bem, renda do consumidor, gostos e preferências do consumidor, preço dos bens relacionados e expectativas sobre o futuro destas variáveis (Passos \& Nogami, 2005). A quantidade demandada de um bem ou serviço reage negativamente ao aumento do seu preço, pressupondo-se que tudo o mais que possa afetar a demanda permaneça constante (Soares, 2008).

A oferta de um determinado bem é a quantidade deste bem que os produtores estão dispostos a vender a determinado preço, mantendo-se constantes quaisquer fatores que possam afetar a quantidade ofertada (Pindyck \& Rubinfeld, 2005). Normalmente, a oferta depende do preço do bem ou serviço, do preço dos fatores de produção, da tecnologia empregada na produção, do preço dos bens substitutos ou complementares, das condições climáticas (no caso de produtos agrícolas) e das expectativas sobre o futuro destas variáveis. A lei geral da oferta diz que a oferta de um produto ou serviço, em determinado período de tempo, varia na razão direta da variação de preços desse produto ou serviço, a partir de um nível de preços tal que seja suficiente para fazer face ao custo de produção até o limite superior de pleno emprego dos fatores de produção, quando se tornará constante, ainda que os preços em referência possam continuar oscilando, mantidas constantes as demais condições (Passos \& Nogami, 2005).

O preço de equilíbrio de mercado é aquele que ocorre no ponto onde a quantidade do bem que os compradores desejam e podem comprar é exatamente igual à quantidade que os vendedores desejam e podem vender. Ou seja, o preço de equilíbrio de mercado ocorre no ponto de interseção das curvas de demanda e oferta (Mankiw, 2009).

De acordo com as tendências de equilíbrio de mercado apresentadas em Pindyck \& Rubinfeld (2005), ao se analisar as exportações de um produto ao longo de um determinado tempo, uma variação positiva em sua quantidade exportada $(q)$ e preço $(p)$ indica que houve aumento da demanda $(D)$ no período. Caso haja queda na quantidade exportada e no preço do produto, é sinal que a demanda diminuiu. Em caso de aumento na quantidade e diminuição de preço, houve aumento na oferta durante o período. Por fim, se a quantidade exportada diminuiu e o preço aumentou, é sinal de queda na oferta. Estes comportamentos estão resumidos na Tabela 1 , como vistos em Almeida et al. (2009).
Tabela 1. Relação dos deslocamentos das curvas de oferta $(O)$ e demanda $(D)$ conforme os sinais das taxas de crescimento do preço $(p)$ e quantidade $(q)$ exportada.

\begin{tabular}{cc}
\hline $\begin{array}{c}\text { Direções das taxas de crescimento da } \\
\text { quantidade e do preço }\end{array}$ & $\begin{array}{c}\text { Tipo de } \\
\text { enquadramento }\end{array}$ \\
\hline$\uparrow q \uparrow p$ & $\uparrow D$ \\
$\downarrow q \downarrow p$ & $\downarrow D$ \\
$\uparrow q \downarrow p$ & $\uparrow O$ \\
$\downarrow q \uparrow p$ & $\downarrow O$ \\
\hline
\end{tabular}

Fonte: adaptado de Almeida et al. (2009)

\section{Referencial analítico}

Foram estimados modelos de tendência da variação anual para preço e quantidade exportada para os principais produtos florestais exportados pelo Brasil. O cálculo das taxas de variação anual foi feito conforme procedimento presente em Gujarati (2000). Segundo o autor, sendo $Y$ o preço ou quantidade de um produto, sua variação ao longo do tempo pode ser descrita pela equação 1 .

$$
Y_{\mathrm{t}}=Y_{0}(1+r)^{t}
$$

Onde $Y_{\mathrm{t}}$ é o preço $(p)$ ou quantidade $(q)$ no tempo $t$, $Y_{0}$ é o preço ou quantidade no tempo $0, r$ é a taxa média de variação de $Y$ e $t$ é o tempo em relação ao período inicial (zero), em anos. Logaritmizando (1) tem-se a expressão 2 .

$$
\ln Y_{\mathrm{t}}=\ln Y_{0}+\ln (1+r) t
$$

Seja $\ln (1+r)=\beta_{1}$ é possível estimar $\beta_{1}$ através do modelo 3.

$$
\ln Y_{\mathrm{t}}=\ln Y_{0}+\beta_{1} t
$$

Isolando-se $r$ em $\ln (1+r)=\beta_{1}$, tem-se:

$$
\mathrm{r}=\mathrm{e}^{\beta 1}-1
$$

A taxa $r$ foi obtida a partir do ajuste do modelo (3) aos dados de preço e quantidade exportada dos produtos florestais, e posterior aplicação da expressão 4.

Baseando-se nos sinais da taxa para cada produto, foi determinado o comportamento da oferta e da demanda conforme a Tabela 1. Gráficos do comportamento da quantidade exportada e do preço em relação ao tempo também foram gerados para análise. 


\section{Fonte de dados}

Os dados para este estudo foram obtidos através da Food and Agriculture Organization (Fao, 2015). Buscou-se utilizar dados de um intervalo de tempo que abrangesse de um ano de estabelecimento da atual moeda do Brasil, até o limite de dados disponíveis à época do estudo. Este intervalo correspondeu ao período entre 1995 a 2013.

A princípio, consideraram-se como "principais produtos florestais" os quatro produtos que tiveram maior valor de exportações (em US\$) pelo Brasil no ano de 2013:

Painéis de madeira: MDF, HDF, outros painéis como chapas isolantes, todos os tipos de madeira compensada, excluindo material de construção laminado (ex: madeira laminada colada).

Madeira serrada: madeira serrada que foi produzida a partir de madeira em tora, tanto nacional quanto importada, e que excede $6 \mathrm{~mm}$ de espessura.

Polpa de celulose: polpa obtida por processo sulfato (kraft), soda ou sulfito e celulose solúvel.

Papel: papéis para impressão (excluindo papeljornal); papelão; e papel para uso especial em indústria (ex: papel para cigarro). Não inclui papel sanitário.

Os preços dos produtos foram calculados pela razão entre o valor e quantidade exportada e, depois, deflacionados pelo índice de preços ao consumidor sobre o dólar ao longo do tempo, disponível no Bureau of Labor Statistics (BLS) (2015).

\section{Resultados e discussão}

As tendências das variáveis de interesse ao longo dos anos de estudo são apresentadas na Figura 1. As exportações de celulose apresentam crescimento acelerado entre 1995 e 2013, mesmo após a crise financeira de 2008. Todavia, as exportações anuais de papel se mantiveram um tanto constantes, partindo $1.000 .000 \mathrm{t}$ e não ultrapassando $2.000 .000 \mathrm{t}$, e as exportações de madeira serrada e painéis de madeira aumentaram até o ano de 2005, com queda após este período. Os preços dos produtos tiveram tendência geral de queda de 1995 a 2013, havendo redução em todos durante a crise financeira em 2009, com moderada recuperação a partir de 2010.

As taxas de variação $(r)$ calculadas para quantidade exportada e preço no período de 1995 a 2013 apresentaram comportamento semelhante para a maior parte dos produtos analisados (Tabela 2). Com exceção da madeira serrada, a tendência para os demais produtos analisados foi de aumento na quantidade exportada $(q)$ e diminuição no preço $(p)$.

Houve um deslocamento da curva da oferta de polpa de celulose, painéis de madeira e papel para a direita, ou seja, a oferta destes produtos feita pelo Brasil no mercado internacional aumentou no período. Por outro lado, para madeira serrada houve deslocamento da curva de demanda para a esquerda, indicando queda na demanda deste produto brasileiro no mercado internacional entre 1995 e 2013.
A

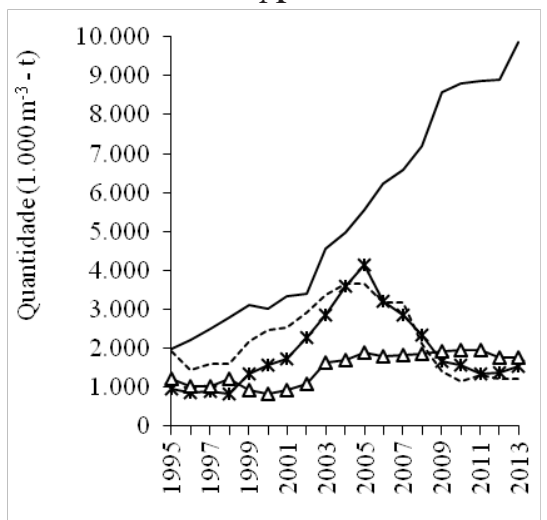

Ano
B

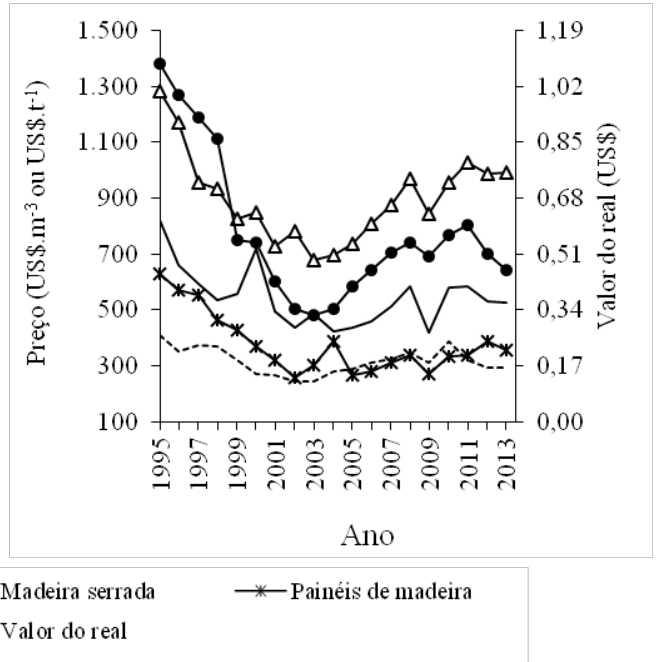

Figura 1 - Comportamento da quantidade (A) e do preço (B) dos principais produtos florestais exportados pelo Brasil ao longo do período de 1995 a 2013, bem como o valor do real em relação ao dólar neste período. 
Tabela 2. Taxa de variação da quantidade exportada $\left(r_{\mathrm{q}}\right)$ e do preço $\left(r_{\mathrm{p}}\right)$ para os principais produtos florestais exportados pelo Brasil no período de 1995 a 2013.

\begin{tabular}{lccc}
\hline \multicolumn{1}{c}{ Item exportado } & $\mathbf{r}_{\mathbf{q}}(\mathbf{\%})$ & $\mathbf{r}_{\mathbf{p}} \mathbf{( \% )}$ & $\begin{array}{c}\text { Tipo de } \\
\text { enquadramento }\end{array}$ \\
\hline Polpa de celulose & 10,13 & $-3,73$ & $\uparrow$ Oferta \\
Madeira serrada & $-0,01$ & $-2,35$ & $\downarrow$ Demanda \\
Painéis de madeira & 5,94 & $-7,35$ & $\uparrow$ Oferta \\
Papel & 2,60 & $-5,10$ & $\uparrow$ Oferta \\
\hline
\end{tabular}

Bons desempenhos nas exportações de commodities florestais brasileiras normalmente ocorrem por vantagem apoiada principalmente em aspectos endógenos, como baixo custo de produção e taxa de câmbio favorável, como mencionado por Noce et al. (2003) para madeira serrada e Medeiros \& Fontes (1994) para celulose. Esta situação é chamada de vantagem competitiva que, segundo Porter (1991), ocorre quando uma empresa encontra meios de obter produtos a baixo custo em relação ao seu concorrente, sendo capaz de dispor no mercado a preços diferenciados para os compradores. Valverde et al. (2004) também citam a desvalorização do câmbio brasileiro (câmbio favorável) e a alta produtividade das florestas (baixo custo de produção) como fatores determinantes do sucesso do setor florestal no mercado internacional, principalmente em relação à indústria de papel e celulose.

A economia do setor florestal brasileiro até o ano de 1965 era pouco expressiva e os investimentos em projetos de reflorestamento eram de baixa rentabilidade com um longo prazo de maturação e de elevados riscos. A área florestada cresceu de 1965 a 1988 por meio dos incentivos fiscais e também da obrigação legal de auto-suprimento imposta às empresas que consumiam madeira. Após este período, algumas empresas de boa competência gerencial dentro do segmento se tornaram bem estabelecidas. O processo foi favorecido pelo bom crescimento de espécies dos gêneros Pinus e Eucalyptus no Brasil, bem como a abertura do comércio internacional e o aumento das demanda por produtos do setor. Pouco mais de uma década depois, o país se tornou um dos maiores exportadores de produtos florestais (Valverde et al., 2004). Destacou-se neste cenário a indústria de papel e celulose que, de acordo com Coelho \& Coelho (2013) aumentou sua participação no comércio internacional do ano de 2001 a 2011.

A tendência de aumento das exportações de celulose (Figura 1), com $r_{\mathrm{q}}$ igual a $10,13 \%$ (Tabela 2), indica a expressão do setor no país. É oportuno mencionar que, mesmo com a crise em 2008, de acordo com a Associação Brasileira de Produtores de Florestas Plantadas (Anuário..., 2013), a indústria nacional de celulose cresceu em média 5,7\% ao ano entre 2002 e 2012. Este crescimento foi reflexo do aumento das exportações para Ásia e Europa. Ainda segundo a ABRAF, em 2012 a produção de celulose no Brasil foi igual a 13,9 × $10^{6}$ t, com o país consumindo $5,8 \times 10^{6}$ t. Com a entrada de capital estrangeiro, as indústrias continuaram a investir e a crescer e, segundo a Associação Brasileira de Celulose e Papel (BRACELPA) (2014a, 2014b), em 2013 a produção brasileira de celulose totalizou 15,1 x $10^{6}$ t. A BRACELPA acrescenta que de 2012 a 2013 a produção da celulose de fibra curta cresceu $8,4 \%$, a de fibra longa, 9,9\%, e a produção da pasta mecânica de alto rendimento reduziu 1,1\%. A Europa se manteve como o principal destino da celulose brasileira, com a importação de $41 \%$ do volume exportado, seguida pela Ásia e pela América do Norte, com cerca de 39\% e 20\%, respectivamente.

O setor de papel, que cresceu 1,8\% de 2012 a 2013 , é mais discreto do que o de celulose, que cresceu $8,2 \%$ neste período (Associação Brasileira de Celulose e Papel, 2014a). Desta forma, suas exportações tiveram aumento mais leve (Figura 1), resultando em $r_{\mathrm{q}}$ igual a 2,60\% (Tabela 2). Os dados do setor (Associação Brasileira de Celulose e Papel, 2014b) mostram que o foco das exportações da indústria de papel brasileira é a América Latina, um mercado de menores proporções, quando comparado com Europa e América do Norte. Em 2010, enquanto o consumo aparente de papel dos Estados Unidos era da ordem de $240 \mathrm{~kg}$ per capita e do Canadá igual a $185 \mathrm{~kg}$ per capita, Chile, México e Argentina consumiam 79, 64 e $61 \mathrm{~kg}$ per capita, respectivamente. Aliado a isso, o consumo interno de papel no Brasil também tem aumentado, sendo o destino de mais de $90 \%$ da produção. Por isso, o volume de exportação de papel é modesto quando comparado ao de celulose.

O comportamento das exportações de painéis de madeira e de madeira serrada (Figura 1) tem ligação com o maior importador: Estados Unidos. Macedo \& Roque (2015) comentam que houve crescente aquecimento do mercado imobiliário neste país, com pico em 2005, assim como a procura por novas hipotecas a fim de usar o dinheiro do financiamento para quitar dívidas e aplicar em novos investimentos. No entanto, a partir de 2006 os preços dos imóveis passaram a cair, explicado pelos 
juros do Federal Reserve System (FED), que vinham subindo desde 2004, encareceram o crédito e afastaram compradores. Com isso, a oferta começou a superar a demanda e, desde então, o que se viu foi uma espiral descendente no valor dos imóveis.

Durante a década de 1990, houve uma busca por novas tecnologias para a fabricação de painéis de madeira, sendo observada a instalação de novas unidades produtoras e modernização do pátio industrial do segmento, bem como um investimento de mais de US\$ 1 bilhão (Brasil et al., 2003). Com isso, em 2005 o Brasil destinava aos Estados Unidos 34\% das suas exportações de painéis de madeira e $32 \%$ das suas exportações de madeira serrada. Na época da crise, em 2008 e 2009 , esse volume foi reduzido para médias de $8 \%$ e $16 \%$, respectivamente (Fao, 2015). De acordo com dados da United States Census Bureau (2015), o ápice da expansão imobiliária desse milênio ocorreu em junho de 2005, quando foram requeridas 211,9 mil permissões para construção. O pior ponto da série ocorreu em janeiro de 2011, quando apenas 36,3 mil requisições foram registradas. Em março de 2014, última informação disponível, o investimento em novas residências alcançou 83,7 mil unidades (Amorim, 2014). Com a queda nas exportações após 2005, a taxa $r_{\mathrm{q}}$ para painéis de madeira, que seguia a tendência da $r_{\mathrm{q}}$ para celulose, ficou em 5,94\% (Tabela 2) e a $r_{\mathrm{q}}$ para madeira serrada foi praticamente nula $(-0,0087 \%)$, uma vez que as exportações de 2013 foram menores que as de 1995.

A redução dos preços dos produtos ( $r_{\mathrm{p}}$ negativas) (Tabela 2) pode ser explicada pela desvalorização do real frente ao dólar (Figura 1), uma vez que o comércio internacional das commodities é feito tendo como base a moeda norte americana. Observa-se que a tendência de preços acompanhou a desvalorização do real em 2009, como consequência da crise mundial.

No caso da madeira serrada, os Estados Unidos ainda são o principal destino das exportações brasileiras (Anuário..., 2013). Entretanto, há uma tendência de queda nas exportações, devido à sustentabilidade da indústria madeireira da região norte. Com as pressões ambientais e legislações mais exigentes, torna-se imprescindível a criação de mecanismos de estímulo ao uso racional de florestas nativas no Norte do Brasil e de plantio de florestas nas outras regiões do país, para que a indústria madeireira possa continuar a crescer.

Em relação ao aumento da oferta dos produtos apresentado na Tabela 2, Almeida et al. (2009) afirmam que isto normalmente ocorre em consequência de queda dos custos de produção ou uma melhoria no processo tecnológico e, consequentemente, um aumento da sua produtividade. Este aumento da produtividade permite que o Brasil tenha um menor ciclo de colheita em relação aos demais países. Tal situação está ligada às características de clima e solo brasileiros, condições fundiárias, políticas de investimento em pesquisa e desenvolvimento, verticalização do setor e qualidade de mão de obra empregada no setor florestal (Anuário..., 2013).

\section{Conclusões}

As taxas de variação da quantidade de painéis de madeira, polpa de celulose e papel exportados pelo Brasil, no período de 1993 a 2015, são positivas. Para a quantidade exportada de madeira serrada, a taxa é negativa.

O comportamento positivo das exportações de celulose e papel brasileiros, no período estudado, está relacionado à vantagem competitiva do país para produção de matéria prima e consequentes investimentos no setor. No entanto, as variações nas exportações de painéis de madeira e madeira serrada, de 1995 a 2013, têm relação com a dinâmica da economia dos Estados Unidos.

Para a variação dos preços dos produtos de 1995 a 2013, as taxas são negativas, sendo que as tendências de preço acompanharam as tendências da cotação do dólar.

A oferta de polpa de celulose, painéis de madeira e de papel disponibilizada pelo Brasil no mercado internacional aumentou entre 1995 e 2013, sendo registrada queda de demanda de madeira serrada para o mesmo período.

\section{Agradecimento}

À Coordenação de Aperfeiçoamento de Pessoal de Nível Superior - CAPES pelo apoio financeiro.

\section{Referências}

Almeida, A. N. de et al. Evolução da produção e preço dos principais produtos florestais não madeireiros extrativos do Brasil. Cerne, v. 15, n. 3, p. 282-287, 2009.

Almeida, A. N. de et al. Mercado de madeiras tropicais: substituição na demanda de exportação. Acta Amazonica, v. 40, n. 1, p. 119-126, 2010. DOI: 10.1590/S0044-59672010000100015. 
Anuário Estatístico da ABRAF 2006: ano-base 2005. Brasília, DF, 2006. 80 p. Disponível em: <http://www.bibliotecaflorestal.ufv.br/ bitstream/handle/123456789/3894/anuario-ABRAF-2006.pdf $>$. Acesso em: 17 ago. 2015.

Anuário Estatístico da ABRAF 2013: ano-base 2012. Brasília, DF, 2013. 148 p. Disponível em: <http://www.bibliotecaflorestal.ufv. br/bitstream/handle/123456789/3910/anuario-ABRAF-2013.pdf>. Acesso em: 17 ago. 2015.

Amorim, G. Construção residencial nos Estados Unidos e exportações de produtos de madeira paranaenses. Análise Conjuntural, v. 36, n. 3-4. p. 9-14, 2014.

Associação Brasileira de Celulose e Papel. Dados do Setor: março - 2014. São Paulo: Bracelpa, 2014b. Disponível em: <https://drive. google.com/file/d/0B1SdWW7MVB4QOXFPOThXVzRvVWM/ view>. Acesso em: 07 ago. 2015.

Brasil, A. A. et al. Demanda de exportação de painéis de madeira do Brasil. Floresta, v. 33, n. 2, p. 135-146, 2003. DOI: 10.5380/ rf.v33i2.2268.

Brasil. Ministério do Desenvolvimento, Indústria e Comércio Exterior. Exportação-importação dos setores industriais por intensidade tecnológica. 2015. Disponível em: $<$ http://www.mdic. gov.br/sitio/interna/interna.php? area $=5 \& \mathrm{menu}=1113 \& \mathrm{refr}=608>$. Acesso em: 08 maio 2015.

Bureau of Labor Statistics. CPI inflation calculator: databases, tables \& calculators by subject. Washington, DC, 2015. Disponível em: $<$ http://www.bls.gov/data/inflation calculator.htm $>$. Acesso em: 8 maio 2015 .

Coelho, M. R. F. \& Berger, R. Competitividade das exportações brasileiras de móveis no mercado internacional: uma análise segundo a visão desempenho. Revista da FAE, v. 7, n. 1, p. 51-65, 2004.

Coelho, M. R. F. \& Coelho, M. H. Panorama da indústria de celulose e papel no Brasil: 2001 a 2011. Floresta, v. 43, n. 3, p. 463-474, 2013. DOI: 10.5380/rf.v43i3.28280.

Conjuntura BRACELPA. São Paulo: BRACELPA, n. 64, mar. 2014a. Disponível em: < http://bracelpa.org.br/bra2/sites/default/ files/conjuntura/CB-064.pdf> . Acesso em: 07 ago. 2015.

Fao. FAOSTAT. Disponível em: $<$ http://faostat3.fao.org/download/F/ FO/E>. Acesso em: 8 mar. 2015.

Gomes, F. P. Crescimento da economia e demanda de recursos florestais no Brasil. 2014. 135 f. Dissertação (Mestrado em Economia) - Universidade Federal de Santa Catarina, Florianópolis.

Gujarati, D. N. Econometria básica. 3. ed. São Paulo: Makron Books, 2000. 846 p.

Macedo, A. R. P. \& Roque, C. A. L. Painéis de madeira. Disponível em: <http://www.bndes.gov.br/SiteBNDES/export/sites/default/ bndes_pt/Galerias/Arquivos/conhecimento/bnset/painel.pdf>. Acesso em: 21 maio 2015.

Mankiw, N. G. Introdução à economia. São Paulo: Cengage Learning, 2009. 852 p.
Medeiros, V. X. \& Fontes, R. M. Competitividade das exportações brasileiras de celulose no mercado internacional. Revista Brasileira de Economia e Sociologia Rural, v. 32, n. 2, p. 105-121, 1994.

Noce, R. et al. O desempenho do Brasil nas exportações de madeira serrada. Revista Árvore, v. 27, n. 5, p. 695-700, 2003. DOI: 10.1590/ S0100-67622003000500012.

Passos, C. R. M. \& Nogami, O. Princípios de economia. 5. ed. São Paulo: Pioneira Thomson Learning, 2005. 658 p.

Pindyck, R. S. \& Rubinfeld, D. L. Microeconomia. São Paulo: Prentice Hall, 2005. 641 p.

Porter, M. E. Towards a dynamic theory of strategy. Strategic Management Journal, v. 12, p. 95-117, 1991.

Radicchi, C. C. Competitividade das exportações brasileiras de celulose: uma análise do custo Brasil. 2004. 83 f. Dissertação (Mestrado em Economia Aplicada) - Universidade Federal de Viçosa, Viçosa, MG.

Rezende, J. L. P. et al. O setor florestal brasileiro. Informe Agropecuário, n. 185, p. 7-14, 1996.

Soares, N. S. et al. Análise econométrica da demanda brasileira de importação de borracha natural, de 1964 a 2005. Revista Árvore, v. 32, n. 6, p. 1133-1142, 2008. DOI: 10.1590/S010067622008000600019.

Soares, N. S. et al. Desafios do mercado brasileiro de produtos florestais em 2011. Viçosa, MG: CIFLORESTAS, 2011a. (CIFLORESTAS. Texto técnico, fevereiro 2011). Disponível em: $<$ http://www.ciflorestas.com.br/arquivos/doc_desafios_2011_14335. pdf $>$. Acesso em: 7 maio 2015.

Soares, N. S. et al. Fatores que contribuem para impulsionar o comércio Internacional de produtos florestais brasileiros. Viçosa, MG: CIFLORESTAS, 2011b. (CIFLORESTAS. Texto técnico, janeiro 2011). Disponível em: $<\mathrm{http}$ ://www.ciflorestas. com.br/arquivos/doc_fatores_brasileiros_9240.pdf $>$. Acesso em: 7 maio 2015.

Sistema Nacional de Informações Florestais. Produção florestal: comércio externo. Brasília, DF, 2013. Disponível em: $<$ http://www. florestal.gov.br/snif/producao-florestal/comercio>. Acesso em: 16 mar. 2015.

United States Census Bureau. Population estimates. Washington, DC, 2015 Disponível em: <https://www.census.gov/popest/data/>. Acesso em: 20 maio 2015.

Valverde, S. R. et al. Desempenho das exportações brasileiras de celulose. Revista Árvore, v. 30, n. 6, p. 1017-1023, 2006. DOI: 10.1590/S0100-67622006000600017.

Valverde, S. R. et al. O comportamento do mercado da madeira de eucalipto no Brasil. Biomassa \& Energia, v. 1, n. 4, p. 393-403, 2004.

Valverde, S. R. et al. Impactos dos diferentes acordos de liberalização do comércio internacional no setor florestal brasileiro. Scientia Forestalis, n. 55, p. 117-128, 1999.

Vieira, L. A. N. et al. Dimensionamento do setor florestal em Minas Gerais. Cerne, v. 12, n. 4, p. 389-398, 2006. 
